\title{
What is the conclusion from the DECODE CRT-D study?
}

\author{
Łukasz Januszkiewicz ${ }^{1, \mathrm{D}-\mathrm{E}}$, Piotr Sypien'2,D, Marcin Grabowski ${ }^{2, \mathrm{D}-\mathrm{F}}$ \\ A - Research concept and design, B - Collection and/or assembly of data, C - Data analysis and interpretation, \\ D - Writing the article, E - Critical revision of the article, F - Final approval of article \\ $1^{\text {st }}$ Department of Cardiology, Medical University of Warsaw, Warsaw, Poland \\ $2^{\text {st }}$ Chair and Department of Cardiology, Medical University of Warsaw, Warsaw, Poland.
}

Address for correspondence:

Łukasz Januszkiewicz, 1st Department of Cardiology, Medical University of Warsaw, Warsaw, Poland

email: lukasz.januszkiewicz@wum.edu.pl

Piotr Sypień, 1st Chair and Department of Cardiology, Medical University of Warsaw, Warsaw, Poland.

email: piotr.sypien@gmail.com

Marcin Grabowski, 1st Chair and Department of Cardiology, Medical University of Warsaw, Warsaw, Poland. email: marcin.grabowski@wum.edu.pl

Received: 29.01.2018

Revised: 09.02.2018

Accepted: 11.02 .2018

Final review: 11.02 .2018

DOI: $10.24255 / \mathrm{hbj} / 85212$

\section{Key words:}

cardiac resynchronization therapy, device replacement, ICD indications, device downgrading

\begin{abstract}
Comment on: 'Appropriate implantable cardioverter-defibrillator interventions in cardiac resynchronization therapy-defibrillator (CRT-D) patients undergoing device replacement: time to downgrade from CRT-D to CRT-pacemaker? Insights

The recently published paper by Narducci et al. is focused on the ventricular tachyarrhythmia rate after cardiac resynchronization therapy defibrillator (CRT-D) replacement and an important clinical dilemma: is it rational to downgrade a CRT-D to a CRT pacemaker (CRT-P) [1]? To answer this question the authors analyzed data from the DECODE registry, which was a prospective, single-arm multicenter cohort study designed to assess the long-term follow-up in CRT-D recipients.
\end{abstract}

During device replacement, about $20 \%$ of patients no longer had an indication for the defibrillation function in CRT devices, which is a considerable number. This population might be from real-world clinical practice in the DECODE CRT-D analysis'.

considered as a group which could benefit from downgrading the CRT-D to a CRT-P. During only one-year follow-up after replacement, appropriate device therapy occurred in $7 \%$ of patients with ejection fraction (EF) $>35 \%$, which is similar to the appropriate implantable cardioverter-defibrillator (ICD) therapy rate in patients with a primary prevention indication for an ICD.

The paper by Narducci et al. raises more questions than answers. First, which population of CRT-D recipients could be downgraded to a CRT-P? Second, which patients with EF $>35 \%$ require the defibrillation function? We do not have the answers yet, but ongoing studies might help us to find them. 
One of the most important studies in this area is MADIT S-ICD [2], which was designed to test the hypothesis that post-infarction patients with EF of $36-50 \%$ and diabetes will have benefits from a subcutaneous ICD.

Also, the imperfections of primary prevention ICD implantation guidelines are highlighted by the results of the DECODE study [3]. Ejection fraction $<35 \%$ defines the treatment population in our daily clinical practice and trials. However, we should keep in mind that the majority of sudden cardiac deaths (SCD) occur in subjects with EF $>35 \%$. Moreover, the risk of SCD is declining across major heart failure studies over time.

To sum up, Narducci et al. in the DECODE study emphasize that the risk of appropriate ICD therapy in patients who no longer meet the ICD implantation criteria is not negligible. Sudden cardiac death risk stratification is needed not only in the population of patients with EF $>35 \%$ but also in those with $\mathrm{EF}<35 \%$.

\section{References}

1. Narducci, M.L., Biffi M., Ammendola E., et al. Appropriate implantable cardioverter-defibrillator interventions in cardiac resynchronization therapy-defibrillator (CRT-D) patients undergoing device replacement: time to downgrade from CRT-D to CRT-pacemaker? Insights from real-world clinical practice in the DECODE CRT-D analysis. Europace 2017;0:1-9

2. Ruwald M.H., Solomon S.D., Foster E. et al. Left ventricular ejection fraction normalization in cardiac resynchronization therapy and risk of ventricular arrhythmias and clinical outcomes: results from the Multicenter Automatic Defibrillator Implantation Trial With Cardiac Resynchronization Therapy (MADIT-CRT) trial. Circulation 2014;130:2278-86.

3. Brignole, M., Auricchio, A., Baron-Esquivias G., et al. 2013 ESC Guidelines on cardiac pacing and cardiac resynchronization therapy. European Heart Journal 2013;34:2281-2329 